\title{
II. The Power of the Apfelbaum Analysis
}

Patricia GURIN

Twenty years on, Apfelbaum's analysis of domination and subordination is as fresh and exciting as it originally was. I first read this piece as I was struggling with ways to conceptualize group identity and consciousness among subordinate groups. Like most social psychologists interested in identity, I was influenced by Tajfel's (1978) seminal writings on social identity, and particularly by his treatment of strategies that group members may use to achieve a positive sense of self when their group is disparaged in society. At about that time along came Apfelbaum's article on domination and subordination. Her treatment of the mechanisms of domination, and especially her discussion of regrouping, illuminated my task of dimensionalizing group consciousness, and I have used this piece in nearly all of my writing and teaching ever since. There is no single article that has had as much impact on my thinking as this brilliant piece.

Why is this piece still valuable years after its initial publication? Three features stand out for me. First, Apfelbaum's contention that social psychology treated power as either a personal trait of an individual or at best as an interpersonal issue between individuals remains true today. Second, her discussion of grouping and degrouping is a beautifully nuanced analysis of the structural and cultural processes that are involved in domination and subordination. Third, her focus not only on mechanisms of domination but also on regrouping strategies provides a much needed balance between structural determination and agency of the actor. The tension between social determination and personal agency is no less important now than it was 20 years ago.

Feminism \& Psychology (C) 1999 SAGE (London, Thousand Oaks and New Delhi), Vol. 9(3): 278-281.

[0959-3535(199908)9:3;278-281;009261] 
It might not have been obvious to feminist scholars when the Apfelbaum article was published that social psychology needed to be challenged to deal with intergroup power. Feminist scholars had already made power the central issue in gender relations. Feminist psychologist Jean Baker Miller had in fact provided a conceptualization of domination and subordination in her book, Toward a New Psychology of Women, that was similar to Apfelbaum's and published at about the same time (1976). Since the 1970s, feminist scholars have offered numerous rich depictions of power as a relational issue in intergroup life. This was not true of social psychology.

Even today, most social psychological theories of intergroup relations fail to talk about power at all; an important exception is the work of Sidanius and his colleagues (see Sidanius et al., 1994). Moreover, when power is discussed in the intergroup literature, it is nearly always interpersonal rather than intergroup power. In part, this focus on interpersonal power comes from our dependence in social psychology on the experimental method. It is much easier to manipulate power in the laboratory as a difference between individuals than as a structural difference between groups of people (an important conception is the work of Gamson [1968], who successfully created intergroup power in the laboratory). Today, even when real-world power differentials guide experimental work (for example when power is conceived as an unequal relationship between teachers and students [Snodgrass, 1992], or between supervisors and workers, [Humphrey, 1985]), the experimental manipulation nearly always involves just a dyad rather than multiple members of two groups. Furthermore, loath to lose the controls provided in the laboratory, experimentalists are often suspicious of field studies of natural groups who differ in power and too often attempt to reduce power differentials to something else. A reviewer of a recent piece that I wrote with Tim Peng, Gretchen Lopez and Ratnesh Nagda on power, identity and intergroup relations (in press) questioned why we were using African-Americans and whites as examples of subordinate and dominant groups. Was it because these groups differed in relative size in the university setting where this study was conducted, the reviewer asked? This reductionist tendency in social psychology, its continued commitment to laboratory studies and thus inevitably to examination of interpersonal power, and the relative inattention to power in social psychological research continue to make the Apfelbaum arguments as important today as they were 20 years ago.

\section{SENSITIVITY TO STRUCTURAL AND CULTURAL PROCESSES IN THE DYNAMICS OF DOMINATION-SUBORDINATION}

Apfelbaum challenges us to study how domination is created and maintained. She provides an extremely thoughtful analysis of the mechanisms that groups with 
more resources, rights and privileges use to structure their relationships with other groups, and of the cultural mechanisms they use to protect and perpetuate their advantages. Her analysis takes us much beyond the idea that mere categorization into groups can produce stereotyping and discrimination. More powerful groups seize on (or even create) differences between them and others to insure their advantages. As Memmi (1968: 1887) argued in Attempt at a Definition: Dominated Man, 'It is not the difference which always entails racism; it is racism which makes use of the difference'. Difference results in domination when powerful groups use difference - when they group others as different from themselves, then mark, label, brand and stigmatize the groups who are different, and finally use all of these mechanisms to exclude the 'other'. Apfelbaum goes further yet, arguing that grouping mechanisms alone do not provide stable dominant-subordinate relations. Instead, having differentiated themselves from others, dominant groups then use degrouping mechanisms to ensure that subordinate groups will not use their grouping and potential solidarity for revolution. Degrouping mechanisms (creating a mythical standard, applying it as a universal law, denying difference and reinforcing individualism) are especially effective in perpetuating domination. They legitimate the dominant group's privileges, embed the unequal relationship between groups in the cultural fabric of society, thereby obscuring inequality, and get the subordinated groups to accept their disadvantages. In grouping and degrouping, we have a superb analysis of structural and cultural processes and how they mutually reinforce each other to create and perpetuate domination.

Members of subordinate groups do not always accept their subordinate position. They often resist. Sometimes resistance is individual, indirect and disguised. Actions apparently designed to accommodate and please the dominant group in fact often contain hidden defiance. Folk tales, jokes and stories are often based on how the landowner, boss or husband is outwitted and doesn't even know he has been ridiculed (Miller, 1976). Sometimes resistance is collective, direct and overt. Although Apfelbaum did not endeavor to explain when actors resist in either of these ways, she saw the absolutely critical point that analysis of domination relations must include an analysis of individual and collective agency. In my course, Race, Ethnicity and Racism, which I teach with Steve Sumida of the English Department, the Apfelbaum analysis of domination relations provides the central theoretical framework for positioning racism as one form of domination. It is the first article the students read as we lay out the basic concepts of the course. Then we examine macro-modes of domination that have operated more for some groups than for others: slavery and terror for African-Americans; removal and genocide for Native Americans; colonization, conquest and immigration for Latino Americans; exclusion for Asian-Americans; and assimilation for European-Americans. We further examine micro-modes of domination that historically have operated (and currently do) for each of these groups, using Apfelbaum's grouping and degrouping mechanisms as the primary analytic tool. Finally, for each of these groups we read poetry, short stories and essays, the 
humanities approach in the course, to bring forward the voices of the subordinates as they resist and express agency in both direct and indirect ways. Students write papers on the ways in which domination relations are created, maintained and changed by the actions of both dominants and subordinates. The Apfelbaum article frames the central concepts and structure of the course. Republishing this important article will certainly give it much deserved attention by a new group of scholars, but I am proud to have kept it alive over time for the many students I have taught in this and other courses.

ADDRESS: Patricia GURIN, University of Michigan, Department of Psychology, 525 East University Avenue, Ann Arbor, MI 48109-1109, USA. [email: pgurin@umich.edu] 